Corrigendum

\title{
Corrigendum to "Anomalous Consistency in Mild Cognitive Impairment: A complex networks approach" [Chaos Solitons Fract. J. 70 (2014) 144-155]
}

\author{
J.H. Martínez ${ }^{\mathrm{a}, \mathrm{b}, *}$, P. Ariza $^{\mathrm{c}}$, M. Zanin ${ }^{\mathrm{d}, \mathrm{e}}$, D. Papo ${ }^{\mathrm{c}}$, F. Maestú ${ }^{\mathrm{f}}$, J.M. Pastor $^{\mathrm{a}}$, R. Bajo ${ }^{\mathrm{f}}$, \\ Stefano Boccaletti ${ }^{g}$, J.M. Buldú ${ }^{\text {h,c }}$
}

${ }^{a}$ Complex Systems Group, Technical University of Madrid, Madrid, Spain

${ }^{\mathrm{b}}$ Modelling and Simulation Laboratory, Universidad del Rosario de Colombia, Bogotá, Colombia

${ }^{\mathrm{c}}$ Laboratory of Biological Networks, Centre for Biomedical Technology (UPM-URJC), Madrid, Spain

${ }^{\mathrm{d}}$ Faculdade de Ciências e Tecnologia, Departamento de Engenharia Electrotécnica, Universidade Nova de Lisboa, Lisboa, Portugal

${ }^{\mathrm{e}}$ The INNAXIS foundation and Research Institute, Madrid, Spain

${ }_{\mathrm{f}}^{\mathrm{f}}$ Laboratory of Cognitive and Computational Neuroscience, Centre for Biomedical Technology (UPM-UCM), Madrid, Spain

${ }^{\mathrm{g}}$ CNR-Istituto dei Sistemi Complessi, Via Madonna del Piano, 10, 50019 Sesto Fiorentino, Italy

${ }^{\mathrm{h}}$ Complex Systems Group, Universidad Rey Juan Carlos, Madrid, Spain

Affiliation of Dr. D. Papo is not (f) but (c). Also the (f) institution disappears from the paper. Therefore, all affiliations from (f) will change its letter code.

Affiliations of Dr. J.M. Buldú change and are (h) and (c).

The reference number 21 had been published this year so, the new reference must be written as:

Zanin M, Alcazar J, Carbajosa J, Paez M, Papo D, Sousa P, Menasalvas E, Boccaletti S. Parenclitic networks: uncovering new functions in biological data. Scientific Reports 2014;4:5112.

The authors would like to apologize for any inconvenience caused.

DOI of original article: http://dx.doi.org/10.1016/j.chaos.2014.10.013

* Corresponding author at: Complex Systems Group, Technical University of Madrid, Madrid, Spain.

E-mail addresses: jh.martinez@alumnos.upm.es, johemart@gmail.com (J.H. Martínez). 